\title{
UNIVERSITYOF
}

FORWARD

THINKING

WESTMINSTER用

WestminsterResearch

http://www.westminster.ac.uk/westminsterresearch

Highly linear reconfigurable UWB filters with independently controlled dual bandnotch

Ahmad, W. and Budimir, D.

This is the peer reviewed version of the following article: Ahmad, W. and Budimir, D. 2016. Highly linear reconfigurable UWB filters with independently controlled dual bandnotch. Microwave and Optical Technology Letters. 58 (11), which has been published in final form at

https://dx.doi.org/10.1002/mop.30113.

This article may be used for non-commercial purposes in accordance with Wiley Terms and Conditions for Self-Archiving.

The WestminsterResearch online digital archive at the University of Westminster aims to make the research output of the University available to a wider audience. Copyright and Moral Rights remain with the authors and/or copyright owners.

Whilst further distribution of specific materials from within this archive is forbidden, you may freely distribute the URL of WestminsterResearch: ((http://westminsterresearch.wmin.ac.uk/)).

In case of abuse or copyright appearing without permission e-mail repository@westminster.ac.uk 


\section{Highly Linear Reconfigurable UWB Filters with Independently Controlled Dual Bandnotch}

\begin{tabular}{|r|l|}
\hline Journal: & Microwave and Optical Technology Letters \\
\hline Manuscript ID & Draft \\
\hline Wiley - Manuscript type: & Research Article \\
\hline Complete List of Authors: & $\begin{array}{l}\text { Ahmad, Waqas; University of Westminster, Wireless Communications } \\
\text { Research Group } \\
\text { Budimir, Djuradj; University of Westminster, Wireless Communications } \\
\text { Research Group }\end{array}$ \\
\hline Keywords: & $\begin{array}{l}\text { reconfigurable filters; uwb filters; bandpass filters, graphene switches; } \\
\text { graphene; pin diodes; bandnotch; linear filters. }\end{array}$ \\
\hline & \multicolumn{2}{|l}{} \\
\hline
\end{tabular}

SCHOLARONE ${ }^{\text {m }}$

Manuscripts 


\title{
Highly Linear Reconfigurable UWB Filters with Independently Controlled Dual Bandnotch
}

\author{
Waqas Ahmad and Djuradj Budimir \\ Wireless Communications Research Group, Faculty of Science and Technology, University \\ of Westminster, 115 New Cavendish Street, London, W1W 6UW, UK
}

Abstract: This letter proposes a high-linearity reconfigurable lower ultra-wideband (3.1$5.25 \mathrm{GHz}$ ) filter with independently controlled dual bandnotch at WiMAX $3.5 \mathrm{GHz}$ band and satellite communication systems $4.2 \mathrm{GHz}$ band. Reconfigurability has been achieved by the implementation of Graphene based switches (simulation only) and PIN diodes (measurements). The simulation and measurement results in OFF state show an entire bandpass response from $3.1 \mathrm{GHz}$ to $5.25 \mathrm{GHz}$ and with a very low insertion loss. In ON state, the results show that sharp rejections at $3.5 \mathrm{GHz}$ and $4.2 \mathrm{GHz}$ are achieved, with a low passband insertion loss. The two bandnotch operate independently of each other; thus allowing to control the behaviour of the required bandnotch. The third order intermodulation products were also measured in OFF and ON states and the linearity results have been presented. The filter is able to achieve a high performance with good linearity and no significant loss.

Index Term - reconfigurable filters; uwb filters; bandpass filters; graphene switches; graphene; pin diodes; bandnotch; linear filters.

\section{INTRODUCTION}

Of late, wide-ranging research, improvement and progress have been focused on the use of ultra-wideband (UWB) systems. For the advancement of communication devices and systems, high-linearity UWB filters have experienced an increased demand. Since the unlicensed 3.1-10.6 GHz band was released for UWB communications of commercial applications [1], the race for the development of this technology has seen a huge surge. The lower UWB, i.e. 3.1-5.25 GHz, covers an extensive frequency range and various wireless bands overlap it; e.g. 3.5 GHz WiMAX and 4.2 GHz C-band satellite communication system bands. These bands cause signal distortion by interfering with the UWB signals resulting in a loss of sensitivity. Hence, filtering is necessary to use the UWB efficiently. An effective and potential solution is to introduce reconfigurable bandnotch within the filters' passband. In 
order to achieve this, several filter configurations have been employed; such as applying coupled stubs [2], terminated resonators [3] stubs [4], embedded bandnotch [5] and shortcircuited quarter-wavelength transmission lines [6]. In [2], the filter has high losses and is capable of only a single bandnotch. The structure in [3] has a fixed bandnotch and not enough rejection. Comparatively high losses and signal distortion are experienced in [4]. In [5], the reconfigurability is not good and does not provide full rejection characteristics. Even though the reconfigurability and rejection characteristics are good in [6], but the bandnotch structure is cascaded with the filter; resulting in a larger area taken by the final circuit. Furthermore, in all the aforementioned works, high linearity has not been a priority in the design.

Because of its unique chemical, thermal, mechanical, electronic and optical properties [7], Graphene has captured the attention of the entire research community. A major factor in this is that Graphene presents a very promising future for the replacement of conventional materials and future electronics [7]. Hence, it has been implemented in a wide range of applications. For example, from Graphene based filters reported in [8] and to antennas in [9]. However, there has been almost no reported work on using Graphene as reconfigurable elements, such as switches for use in achieving reconfigurability in filters.

This letter proposes a highly linear UWB bandpass filter. It also shows how to introduce and control reconfigurability using Graphene based switches as switching elements. PIN diodes, as conventional switching elements, have also been used to validate the reconfigurability results obtained from Graphene based switches and to provide measured results. Measurements show the filter to be able to provide reasonable bandnotch rejections and a high linearity while, at the same time, experiencing low passband losses.

\section{DESIGN OF PROPOSED FILTER STRUCTURE}

\section{A) Layout of the Filter}

Fig. 1 shows the third order reconfigurable bandpass filter. The proposed filter is designed with a $3 \mathrm{~dB}$ passband of 3.1 to $5.25 \mathrm{GHz}$ and a mid-band frequency of $4.17 \mathrm{GHz}$. It is inductively coupled to the source and load and is excited by port 1 and port 2. The filter comprises a $\lambda_{\mathrm{g}} / 2$ resonator positioned outside between a short circuited pair of $\lambda_{\mathrm{g}} / 4$ resonators. The two $\lambda_{\mathrm{g}} / 4$ resonators are folded so as to use the same ground via; thereby allowing the design to be miniaturised. A shunt $\lambda_{\mathrm{g}} / 4$ line, of an impedance $77.8 \Omega$, is connected with the middle of the $\lambda_{\mathrm{g}} / 2$ resonator. The other end of the shunt line leads to the 
middle of an open-circuited $\lambda_{\mathrm{g}} / 2$ line, which lies inside the filter. In all the above instances, $\lambda_{\mathrm{g}}$ is the guided wavelength at $4.17 \mathrm{GHz}$.

The dual bandnotch are introduced within the passband by the coupling of an identical, but inverted, pair of U-shaped resonators. The resonator for the $3.5 \mathrm{GHz}$ bandnotch is coupled with the outer $\lambda_{\mathrm{g}} / 2$ filter resonator, while the resonator for the $4.2 \mathrm{GHz}$ bandnotch is placed inside the filter structure, to be coupled with the inner $\lambda_{\mathrm{g}} / 2$ line. The two resonators are placed in the symmetry plane of the filter. Both resonators are $\lambda_{\mathrm{g}} / 2$ long in length at their respective bandnotch frequencies and are coupled at a gap of $0.3 \mathrm{~mm}$ and build sharp rejections in the desired bands. Since the widths - and thus the impedances - of the feed ports and filter resonators are different, for the efficient power transfer between them, impedance transformation is required. For this purpose, stepped impedance matching is employed.

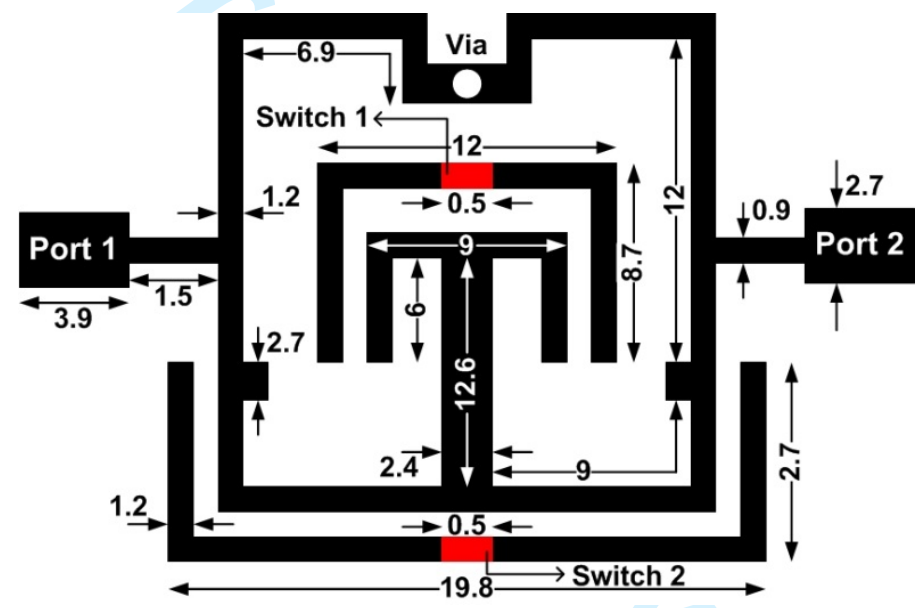

Figure 1 Geometry of the bandpass filter (dimensions in mm).

So as to better understand the structure, the equivalent transmission line model has also been presented in Fig. 2. Before optimisation, lines $A=B=E=F=G=H=I=\lambda_{\mathrm{g}} / 4$ at 4.17 $\mathrm{GHz}$. Lines $\mathrm{C}=\mathrm{D}=\lambda_{\mathrm{g}} / 4$ at $4.2 \mathrm{GHz}$ bandnotch and lines $\mathrm{J}=\mathrm{K}=\lambda_{\mathrm{g}} / 4$ at $3.5 \mathrm{GHz}$ bandnotch. All transmission lines, except the shunt $\lambda_{\mathrm{g}} / 4$ line $\mathrm{G}$, have an impedance of $109.7 \Omega$, leading to a line width of $1.2 \mathrm{~mm}$. The dashed-crosses represent couplings. 


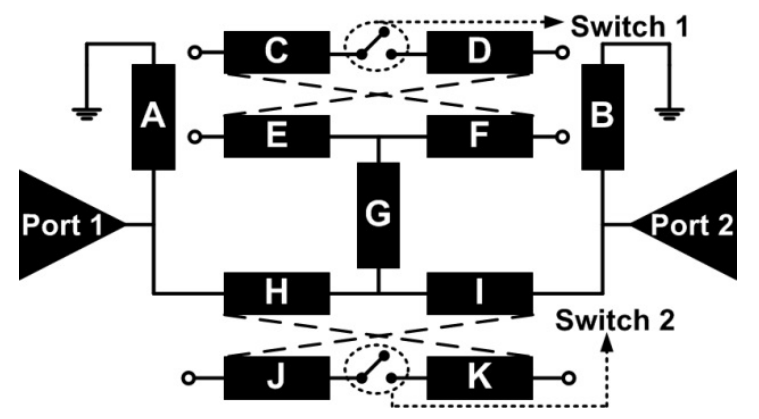

Figure 2 Transmission line model of the bandpass filter.

\section{B) Attainment of Transmission Zeroes}

Line $\mathrm{G}$ produces a transmission zero at $4.06 \mathrm{GHz}$; but since it is connected to lines $\mathrm{E}$ and F, the length increases; causing the transmission zero, TZ1, to move to $2.18 \mathrm{GHz}$. The first harmonic of TZ1 at $2.9 \mathrm{f}_{0}$ produces another transmission zero, TZ3, at $6.3 \mathrm{GHz}$. Lines $\mathrm{C}$ and $\mathrm{D}$ are essentially for the bandnotch at $3.5 \mathrm{GHz}$, but their first harmonic at $1.97 \mathrm{f}_{0}$ produces a transmission zero, TZ4, at $6.9 \mathrm{GHz}$. The first harmonic by lines $\mathrm{J}$ and $\mathrm{K}$ at $2 \mathrm{f}_{0}$ gives a transmission zero, TZ5, at $8.4 \mathrm{GHz}$. Lines $\mathrm{E}$ and $\mathrm{F}$ combined are $\lambda_{\mathrm{g}} / 2$ long and generate a transmission zero TZ2 which varies between 5.63 5.77 GHz. TZ1-TZ4 are shown in Fig. 4 (b). All the generated transmission zeroes significantly improve attenuation and selectivity in the lower and upper stopbands.

\section{C) Attainment of Reconfigurability}

In order to achieve reconfigurable characteristics, gaps of $0.5 \mathrm{~mm}$ are introduced in the centres of the two U-shaped bandnotch resonators. These gaps would then be overlaid with switching elements; such that each resonator would then consist of two transmissions lines conjoined with a switch. This may be seen in Fig. 1. When switching elements are in the OFF state, they work as insulators and no current flows in the coupled resonators at the two bandnotch frequencies; thus no bandnotch is present and a full bandpass response is acquired. In ON state, the switching elements behave like conductors, thereby the two transmission lines of each resonator acting like a single, longer transmission line of a guided halfwavelength at its respective bandnotch frequency and thus dual bandnotch are introduced within the passband. Since the two resonators are coupled independently of each other, each bandnotch may be controlled separately by just using the switch of the required bandnotch. 


\section{D) Modelling of Graphene based Switches and PIN Diodes}

Two different switching elements will be demonstrated and used in the filter in order to achieve the reconfigurable states: Graphene based switches and PIN diodes. These will be placed within the gaps in the two resonators as described in the previous subsection.

Graphene based switches can be implemented by modelling the complex surface impedance of Graphene, as detailed in [2]. Here, similarly, complex surface impedance of Graphene can be realised using (1)-(3). Complex surface impedance modelling takes into account the variable surface resistance and surface reactance of Graphene. Such modelling is faster and uses far less computing and memory resources than customary bulk modelling. OFF state of the switches is when Graphene is unbiased to a chemical potential of $\mu_{\mathrm{c}}=0.0 \mathrm{eV}$ and ON state is obtained when Graphene is biased at a chemical potential of $\mu_{\mathrm{c}}=1.0 \mathrm{eV}$. Therefore, the two reconfigurable states of the Graphene based switches can be easily obtained. To calculate and model the varying surface resistance and surface reactance in both states, MATLAB was used and the resultant data was exported to the electromagnetic simulation software.

$$
\begin{aligned}
& \sigma=-j \frac{q_{e}{ }^{2} K_{b} T}{\pi \hbar^{2}(\omega-j 2 \Gamma)}\left(\frac{\mu_{c}}{K_{b} T}+2 \ln \left(e^{\frac{\mu_{c}}{K_{b} T}}+1\right)\right) \\
& \text { resistance }=\operatorname{Re}\left(\frac{1}{\sigma}\right) \\
& \text { reactance }=\operatorname{Im}\left(\frac{1}{\sigma}\right)
\end{aligned}
$$


In (1)-(3), $\sigma$ is the surface intraband conductivity, $j$ is the imaginary constant, $q_{e}$ is the electron charge, $K_{b}$ is the Boltzmann's constant, $T$ is the temperature, $\hbar$ is the reduced Planck's constant, $\omega$ is the radian frequency, $\Gamma$ is the scattering rate and $\mu_{c}$ is the chemical potential. Scattering rate is defined as $\Gamma=(2 \tau)^{-1}$; where $\tau$ is the average relaxation time. Here, the parameters' values used are $\mathrm{T}=300 \mathrm{~K}, \tau=125 \mathrm{ps}$ and $\Gamma=1.67 \mathrm{x} 10^{11}$ [10].

PIN diodes are popular switching elements; especially in MIC designs, where in addition to high switching speeds, they offer ruggedness and have a low nonlinear distortion [11]. When PIN diodes are in forward bias or ON state, they behave like a small resistance. So that when there are two transmission lines connected to each other by means of a PIN diode, it creates a short circuit between them and they act like a single, longer transmission line. In the ON state, as shown in the equivalent circuit model in Fig. 3 (a), the PIN diodes are essentially current controlled resistors, whose resistance may be described by (4); where $k$ is a device constant, $I_{F}$ is the forward bias current and $\tau$ is the minority carrier lifetime [11]. In contrast, in reverse bias or OFF state, there is no connection between two transmission lines conjoined together with a PIN diode. As illustrated in the equivalent circuit model in Fig. 3 (b) of the OFF state, there is a large series resistance in parallel with a capacitance $C_{P}$, which degrades the high frequency isolation of the device.

$$
\mathrm{R}_{\mathrm{s}}=\frac{k}{\tau \times \mathrm{I}_{\mathrm{F}}}
$$

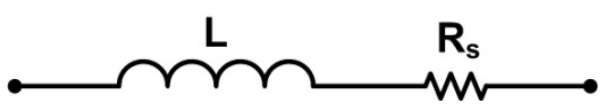

(a)

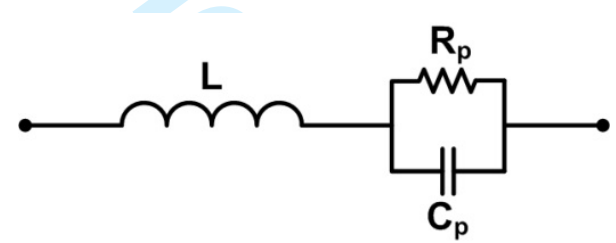

(b)

Figure 3 Equivalent circuit model of PIN diode in (a) switch ON and (b) switch OFF.

Two PIN diodes of model NXP BAP65-02 are employed to match with the switching parameters and have a specification of: a resistance of $0.9 \Omega$, an inductance of $0.6 \mathrm{nH}$ and a capacitance of $0.8 \mathrm{pF}$ [12]. The diodes are switched on by supplying a DC voltage of $3 \mathrm{~V}$ and current of $1 \mathrm{~mA}$ to each diode. The DC blocking capacitance is $33 \mathrm{pF}$ and a resistor of $1 \mathrm{k} \Omega$ 
is used for biasing with each diode. A reverse bias connection gives the OFF state and forward bias results in the ON state.

\section{RESULTS}

The filter in Fig. 3 is designed on a Rogers Duroid 5880 substrate; of a thickness of 1.575 $\mathrm{mm}$, a dielectric permittivity $\varepsilon_{\mathrm{r}}=2.2$ and a loss tangent $\tan \delta=0.0009$. It is simulated by the commercial software programs emSonnet and SonnetLab.

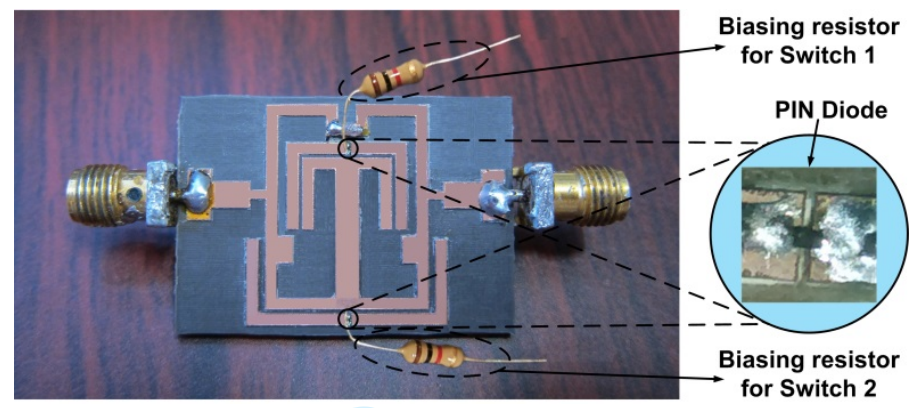

Figure 4 Photograph of the fabricated bandpass filter.

\section{A) S-parameters with PEC Patches}

For an ideal case comparison, the filter was first electromagnetically simulated by covering the gaps, wherein would the actual switches be laid, with perfect electric conducting (PEC) metal patches for switch ON condition and leaving the gaps empty as they are for a switch OFF case. The filter was simulated in states 1, 2, 3 and 4 and the results are presented in Fig. 5 (a), Fig. 5 (b), Fig. 5 (c) and Fig. 5 (d) respectively. State 1 shows a complete bandpass response from 3.1-5.25 GHz. State 2 retains the bandpass but with dual bandnotch at $3.5 \mathrm{GHz}$ and $4.2 \mathrm{GHz}$. State 3 and state 4 only show bandnotch at $4.2 \mathrm{GHz}$ and at $3.5 \mathrm{GHz}$ respectively.

\section{B) S-parameters with Graphene based Switches}

The results in state 1, state 2, state 3 and state 4 are shown in Fig. 5 (a), (b), (c) and (d) respectively. The filter's $3 \mathrm{~dB}$ passband appears to be about 3.14-5.23 GHz according to all results. This almost matches the wanted lower UWB frequency range. In all four states, since the return loss is more than $20 \mathrm{~dB}$, a good matching exists in the filter. The result when the switches are in state 1 shows that no bandnotch exists in the passband. This allows the filter 
to cover the $3.5 \mathrm{GHz}$ and $4.2 \mathrm{GHz}$ bands. The insertion loss in this state is about $0.15 \mathrm{~dB}$. In state 2, an insertion loss of $0.6 \mathrm{~dB}$ is seen in the result. Also, dual bandnotch at $3.49 \mathrm{GHz}$ and 4.22 GHz are present. The rejection of the dual bandnotch is achieved around $30 \mathrm{~dB}$. In state 3 , only one bandnotch is present at $4.22 \mathrm{GHz}$, at $30 \mathrm{~dB}$ rejection, while the other bandnotch is absent. State 4 is reverse: with a bandnotch at $3.51 \mathrm{GHz}$, at $37 \mathrm{~dB}$ loss, only. The passband insertion loss varies between $0.32 \mathrm{~dB}$ in state 3 and $0.48 \mathrm{~dB}$ in state 4 .

\section{C) S-parameters with PIN Diodes}

In the fabricated structure with PIN diodes, Agilent E8361A PNA Network Analyser was used to carry out the measurements of the S-parameters. The results are presented in Fig. 5 (a) for state 1 and in Fig. 5 (b) for state 2. In state 1, no bandnotch exists and the $3 \mathrm{~dB}$ passband is from 3.14-5.35 GHz. The filter's insertion loss is roughly $0.2 \mathrm{~dB}$. In state 2 , the passband is 3.19-5.15 GHz. As also seen in the passband, dual bandnotch are introduced. The obtained rejection at these dual bandnotch is $5 \mathrm{~dB}$ less than the one achieved by the Graphene based switches, i.e. at $25 \mathrm{~dB}$. Furthermore, the dual bandnotch have moved to frequencies of 3.48 GHz and 4.26 GHz. These shifts are caused by the discrepancies in the fabrication. An insertion loss of $0.8 \mathrm{~dB}$ is present in the passband. State 3, presented in Fig. 5 (c), has a passband of 3.14-5.35 GHz and state 4, shown in Fig. 5 (d), has a passband of 3.19-5.2 GHz at an insertion loss of $0.4 \mathrm{~dB}$ and $0.6 \mathrm{~dB}$ respectively. State 3 shows a single bandnotch at $4.28 \mathrm{GHz}\left(\mathrm{S}_{21}=25.5 \mathrm{~dB}\right)$ while state 4 has one at $3.48 \mathrm{GHz}\left(\mathrm{S}_{21}=25 \mathrm{~dB}\right)$ only.

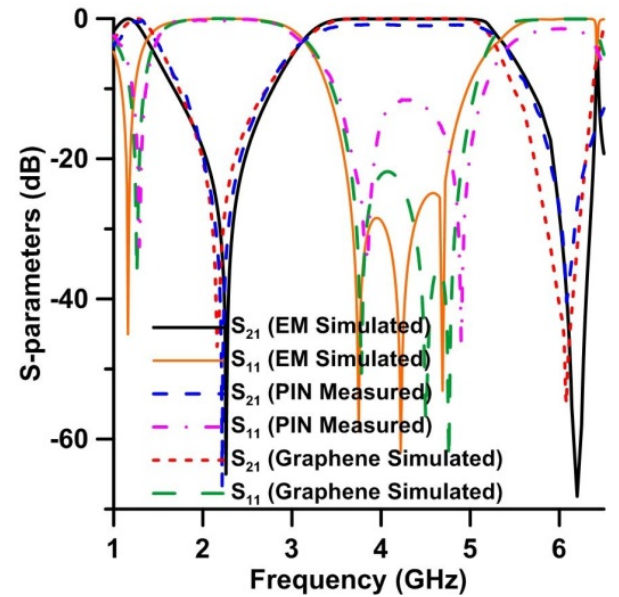

(a)

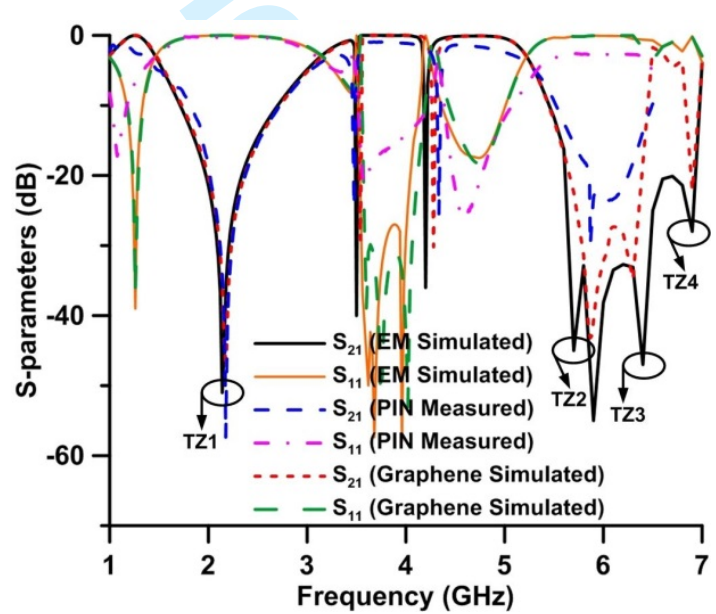

(b) 


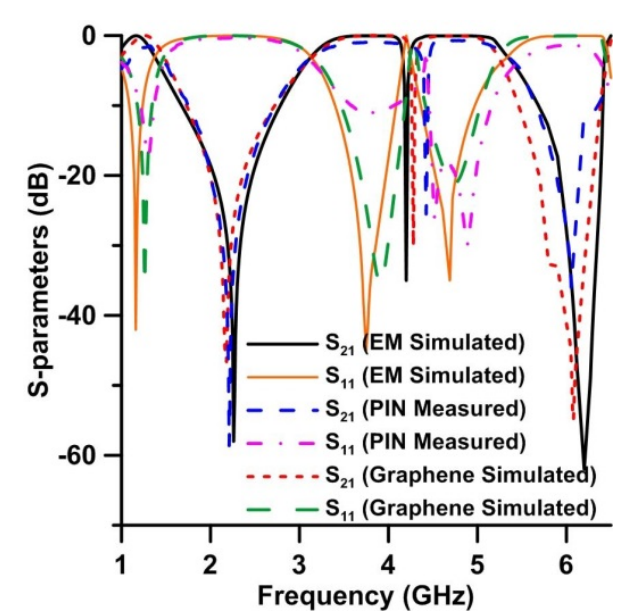

(c)

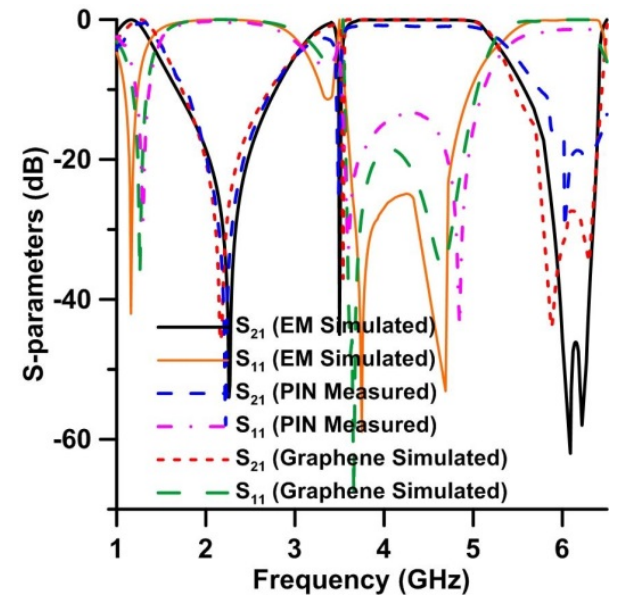

(d)

Figure 5 S-parameters of the filter with the switches in (a) state 1, (b) state 2, (c) state 3 and (d) state 4 .

\section{D) Measured Linearity with PIN Diodes}

The nonlinearity introduced by a PIN diode is a function from (4) of the forward bias current $I_{F}$ and the RF current $i_{f}$. Generally, better linearity may be obtained when the extent of the bias current modulation by the RF current decreases. The modulation effect can be minimised by deliberately operating at a high forward bias current [11].

For the purpose of validating the high linearity characteristics, the filter was gauged by means of a $5 \mathrm{MHz}$ QPSK signal with and without the PIN diodes. Input power between a range of $-25 \mathrm{dBm}$ and $10 \mathrm{dBm}$ resulted in very good linearity. The performance at various passband frequencies in state 1 and state 2 was measured and has been shown in Fig. 6.

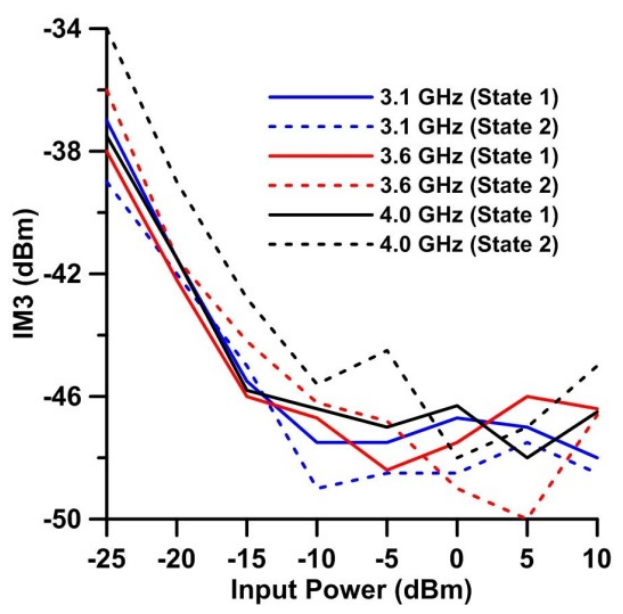

Figure 6 Measured third order intermodulation products in states 1 and 2. 


\section{E) Comparison with Other Works}

Table II presents a comparison of others works in which similar filters were developed.

\begin{tabular}{|c|c|c|c|c|c|c|c|}
\hline Reference & $\begin{array}{l}\text { Filter } \\
\text { Order }\end{array}$ & $\begin{array}{l}\text { Number of } \\
\text { Bandnotch }\end{array}$ & Reconfigurable & $\begin{array}{c}\text { Independently } \\
\text { Controlled } \\
\text { Bandnotch }\end{array}$ & $\begin{array}{c}\text { Filter } \\
\text { Linearity } \\
\text { Investigated }\end{array}$ & $\begin{array}{c}\text { FBW } \\
(\%)\end{array}$ & $\begin{array}{c}\text { Size } \\
\left(\lambda_{\mathrm{g}} \times \lambda_{\mathrm{g}}\right)^{*}\end{array}$ \\
\hline [2] & 3 & 1 & Yes & N/A & Yes & 109.5 & $0.82 \times 0.36$ \\
\hline [3] & 5 & 2 & No & No & No & 111 & $0.57 \times 0.54$ \\
\hline [4] & 3 & 1 & Yes & N/A & No & 100.7 & $0.50 \times 0.50$ \\
\hline [5] & 7 & 1 & Yes & N/A & No & 86.4 & not given \\
\hline [6] & 3 & 1 & Yes & N/A & No & 46.9 & $0.30 \times 0.36$ \\
\hline This Work & 3 & 2 & Yes & Yes & Yes & 51.5 & $0.55 \times 0.61$ \\
\hline
\end{tabular}

Table 2 Comparison of various other works.

\section{CONCLUSION}

A highly linear reconfigurable UWB filter, coupled with two resonators implemented with switches - PIN diodes and Graphene based - is presented. The switches reconfigure the filter between a full bandpass response and a bandpass response with dual bandnotch at $3.5 \mathrm{GHz}$ and 4.2 GHz. The simulation and measurement results of both switching elements in OFF and ON states have been shown. A good agreement is present between the results of the two elements; hence validating the filter concept. These obtained results show no bandnotch in the passband in OFF state; while dual bandnotch are present at $3.5 \mathrm{GHz}$ and $4.2 \mathrm{GHz}$ in $\mathrm{ON}$ state. Two further states are also possible when the two resonators are alternated between OFF and ON positions; hence producing their respective bandnotch only. The highly linear nature of the filter has been shown by experimentally evaluating the linearity using a QPSK signal at various passband frequencies of the PIN diodes based filter.

\section{REFERENCES}

[1] FCC, "Revision of part 15 of the commission's rules regarding ultra-wideband transmission systems,” First Note and Order Federal Communications Commission, pp. 98-153, February 2002.

[2] W. Ahmad and D. Budimir, "Reconfigurable WLAN notch for UWB filters," $44^{\text {th }}$ European Microwave Conference, pp. 1536-1539, October 2014. 
[3] H. Wang, K-W. Tam, S-K. Ho, W. Kang, and W. Wu "Design of ultra-wideband bandpass filters with fixed and reconfigurable notch bands using terminated cross-shaped resonators,” IEEE Transactions on Microwave Theory and Techniques, pp. 1-14, January 2014.

[4] M. F. Karim, Y-X. Guo, Z. N. Chan and L. C. Ong, "Miniaturized reconfigurable and switchable filter from UWB to $2.4 \mathrm{GHz}$ WLAN using PIN diodes”, IEEE MTT-S International Microwave Symposium Digest, pp. 509-512, June 2009.

[5] Y-H. Chun, H. Shaman, and J-S. Hong, "Switchable embedded notch structure for UWB bandpass filter,” IEEE Microwave and Wireless Component Letters, vol. 18, no. 9, pp. 590-592, September 2008.

[6] K. Rabbi, L. Athukorala, C. Panagamuwa, J.C. Vardaxoglou, and D. Budimir, “Compact UWB bandpass filter with reconfigurable notched band,” Electronics Letters, vol. 49, no. 11, pp. 709-711, May 2013.

[7] A. K. Geim and K. S. Novoselov, “The rise of graphene,” Nature Materials, vol. 6, pp. 183-191, March 2007.

[8] M. Danaeifar, N. Granpayeh, A. Mohammadi, and A. Setayesh, "Graphene-based tunable terahertz and infrared band-pass filter,” Applied Optics Letters, vol. 52, no. 22, pp. E6872, August 2013.

[9] L. Pierantoni, M. Dragoman, and D. Mencarelli, “Analysis of a microwave Graphenebased patch antenna,” 43 ${ }^{\text {rd }}$ European Microwave Conference, pp. 381-383, October 2013.

[10] G. W. Hanson, "Dyadic green's functions for an anisotropic non-local model of biased graphene,” IEEE Transactions on Antennas and Propagation, vol. 56, no. 3, pp. 747-757, March 2008.

[11] W. E. Doherty, Jr. and R. D. Joos, "PIN Diode RF Switches,” in The PIN Diode Circuit Designers’ Handbook, Watertown: Microsemi Corp., 1998, pp. 18-20.

[12] NXP, PIN Diode BAP65-02 Datasheet [Online]. Available: http://www.nxp.com/documents/data_sheet/BAP65-02.pdf 